\title{
Analysis and proposition of layout in the lean perspective: case study in a small production company of aluminum furniture
}

\author{
Tiago Fonseca Albuquerque Cavalcanti Sigahi', Caio Yamamoto Lemos ${ }^{2}$, Camila Isabel Maia Ramos ${ }^{3}$ \\ 1,2,3 Universidade Federal de São Carlos (UFSCar/Sorocaba)
}

Email: tiago_sigahi@hotmail.com, caiocom@hotmail.com, camila.maia90@g mail.com

Received: February 7th, 2017

Accepted: March $23^{\text {th }}, 2017$

\section{ABSTRACT}

Published: June $30^{\text {th }}, 2017$

The present work has the objective of presenting the analysis and the proposal of a new layout from the perspective of lean manufacturing from the case of a company in the field of production of aluminum furniture. Direct observation of the factory floor and interviews with employees and owners

Copyright $(2016$ by authors and Institute of Technology Galileo of Amazon (ITEGAM). This work is licensed under the Creative Commons Attribution International License (CC BY 4.0).

http://creativecommons.org/lic enses/by/4.0/ were carried out to collect data and process mapping. Based on the 5 s concepts, improveme nts were proposed regarding the use (elimination of what was not useful for jobs), organization (establishment of correct place to store tools and work in process), cleaning (identification of potential failures related to quality and safety), standardization (establishment of internal norms) and discipline (perpetuation of continuous improvement). It was also contributed by analyzing the cycle times of each step of the process (cutting, folding, welding, drilling and sanding) and takt time, identifying the need for three supermarkets, using the concept of square kanban. Finally, based on the previous steps, the main contribution of the study was the proposition of a new layout, where two production cells were determined, resulting in benefits such as reduction of distances, reduction of unnecessary movements, greater simplification of work, environment cleaner, safer and more organized.

Keywords: Entrepreneurship, Micro and Small Business, Innovation, Local Innovation Agents .

\section{Análise e proposição de layout na perspectiva lean: estudo de caso em uma pequena empresa produtora de móveis de alumínio \\ RESUMO}

O presente trabalho tem como objetivo apresentar a análise e a proposição de um novo layout sob a ótica do lean manufacturing a partir do caso de uma empresa do ramo de produção de móveis de alumínio. Realizou-se observação direta do chão de fábrica e entrevistas com funcionários e proprietário para coleta dados e mapeamento do processo. Fundamentadas nos conceitos do 5S, melhorias foram propostas quanto à utilização (eliminação do que não era útil aos postos de trabalho), organização (estabelecimento de local correto para armazenar ferramentas e work in process), limpeza (identificação de potenciais falhas relacionadas à qualidade e segurança), padronização (estabelecimento de normas internas) e disciplina (perpetuação da melhoria contínua). Contribuiu -se também através da análise dos tempos de ciclo de cada etapa do processo (corte, dobragem, soldagem, furação e lixamento) e do takt time, identificando-se a necessidade de três supermercados, utilizandose o conceito de quadrado kanban. Por fim, apoiando-se nas etapas anteriores, a principal contribuição do estudo foi a proposição de um novo layout, onde foram determinadas duas células de produção, resultando em benefícios como redução de distâncias, redução de movimentações desnecessárias, maior simplificação do trabalho, ambiente mais limpo, seguro e organizado.

Palavras Chaves: Layout, Arranjo físico, Lean manufacturing, Produção enxuta.

\section{INTRODUÇÃO}

O estudo sobre a instalação de uma linha de produção sempre foi uma das principais áreas de pesquisa da engenharia industrial [1], uma vez que o arranjo físico possui grande influência no desempenho do sistema produtivo como um todo [2][3]. Uma má disposição dos recursos de transformação pode levar, entre outros problemas, a padrões de fluxo longos ou confusos, work in process, filas de clientes, tempos de processamento longos, operações inflexíveis, além de aumentar os custos de processamento, podendo comprometero prazo de atendimento dos pedidos [4].

$\mathrm{O}$ setor moveleiro nacional tem experimentado significativos crescimento de demanda e expansão econômica. Nos 
últimos dez anos, este setor obteve crescimento superior a $200 \%$, tendo apresentado o seguinte panorama em 2010: mais de 15,25 mil indústrias, 275,6 mil empregados formais, faturamento de 29,72 bilhões de reais e valor total de exportações de US\$ 789,3 milhões [5].

Neste cenário, o presente estudo tem como objetivo apresentar a análise e a proposição de um novo layout sob a ótica do lean manufacturing com base em uma empresa do ramo de produção de móveis de alumínio. Para isso, realiza-se, inicialmente, uma revisão dos conceitos sobre arranjo físico e lean manufacturing. Na sequência, apresenta-se o método de pesquisa e, emseguida, o estudo de caso, abordando-se as oportunidades de melhoria identificadas no diagnóstico inicial e, a partir disso, a proposição de um novo layout. Conclui apresentando as considerações finais.

\section{FUNDAMENTAÇÃO TEÓRICA}

Para [6] apontam o problema de decisão de layout entre as decisões estratégicas, juntamente com o planejamento de produtos, processos e tecnologias.
Planejar o layout (ou arranjo físico) de uma instalação significa tomar decisões sobre a forma como serão dispostos os centros de trabalho (departamento, sala, pessoa, grupo de pessoas, máquinas, equipamentos, bancadas, estações de trabalho, etc.), tendo emvista o objetivo de tornar mais fácil e suave o fluxo de pessoas e/ou materiais [7].

De maneira mais simples, determinar o layout é alocar recursos de maneira mais conveniente para o ambiente de trabalho em questão [4]. De acordo com [4], há uma dupla pressão para a decisão sobre o arranjo físico: a primeira se refere aos aspectos de execução e financeiro, o que faz com que haja certa resistência por parte dos gerentes de produção em realizar mudanças com frequência; a segunda está relacionada às consequências de decisões erradas, as quais podem ter efeitos negativos consideráveis em longo prazo.

Assim, o mesmo autor afirma que se deve seguir um processo de múltiplos estágios, a saber: seleção do tipo de processo, seleção do tipo básico do layout e elaboração do projeto detalhado do layout [4]. A figura 1 mostra o processo de tomada de decisão de arranjo físico.

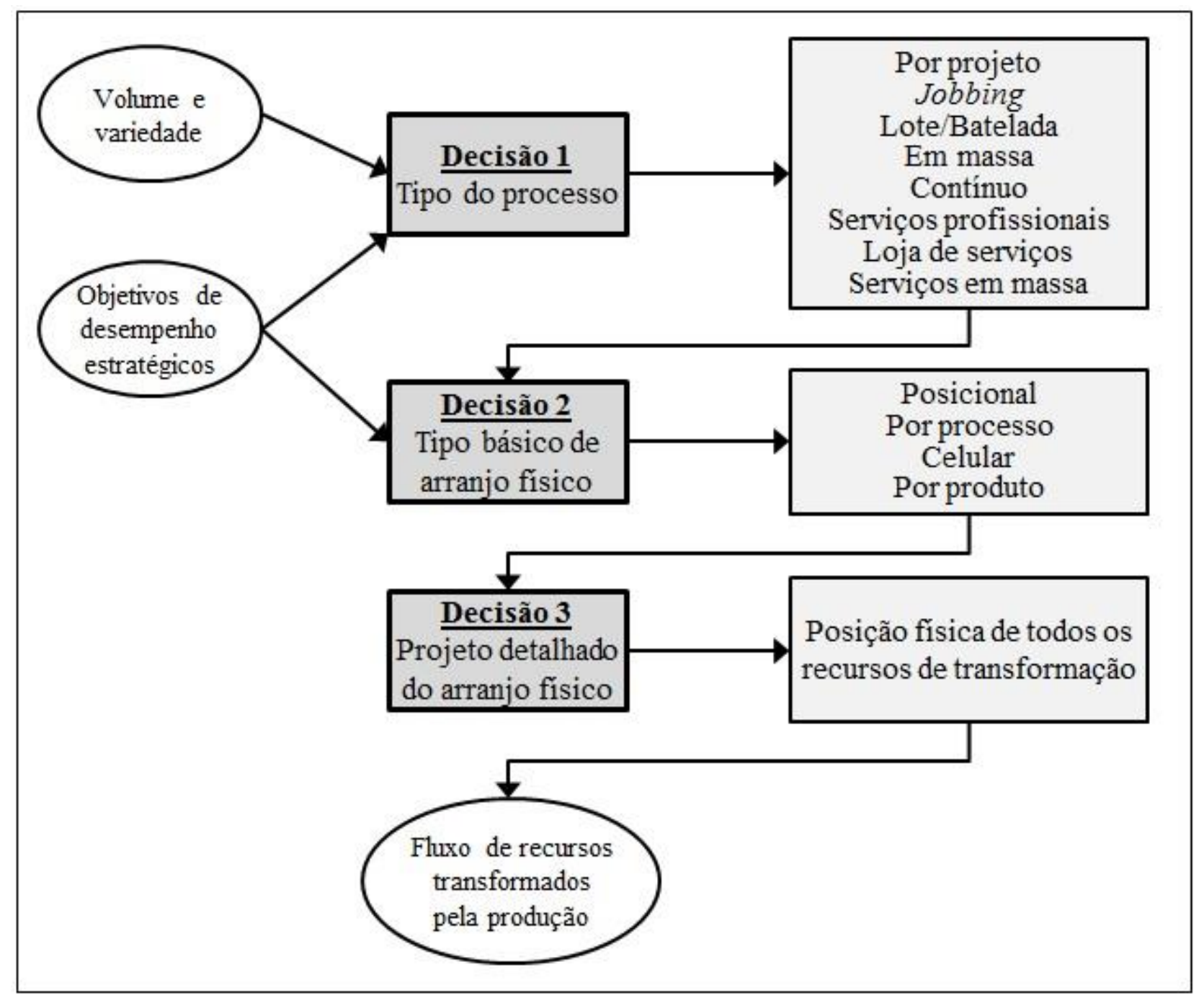

Figura 1: Processo de tomada de decisão de arranjo físico.

Fonte: adaptado de [4]. 
Para Autores como [4][8][9][10], classificam os arranjos físicos em quatro tipos básicos, resumidos no quadro 1:

Quadro 1: Tipos, descrição e exemplos de arranjos físicos.

\begin{tabular}{|c|c|c|}
\hline Arranjo físico & Descrição & Exemplos \\
\hline Por produto & $\begin{array}{l}\text { Os recursos são configurados em uma sequência } \\
\text { específica para determinado produto ou família de } \\
\text { produtos. Neste arranjo, o produto segue um roteiro pré- } \\
\text { definido na qual os recursos transformadores já foram } \\
\text { distribuídos para este fim. }\end{array}$ & $\begin{array}{l}\text { Indústrias montadoras, indústrias } \\
\text { alimentícias, frigoríficos, serviços } \\
\text { de restaurante por quilo }\end{array}$ \\
\hline $\begin{array}{l}\text { Por processo } \\
\text { ou funcional }\end{array}$ & $\begin{array}{l}\text { Recursos similares são agrupados e mantidos uns } \\
\text { próximos aos outros. Este tipo de arranjo é utilizado } \\
\text { quando os fluxos são variados e ocorrem de maneira } \\
\text { aleatória, tornando pos sível realizar vários roteiros e } \\
\text { fazendo uso da mesma estrutura. }\end{array}$ & $\begin{array}{l}\text { Hos pitais, serviços de confecção } \\
\text { de moldes e ferramentas, lojas } \\
\text { comerciais }\end{array}$ \\
\hline Celular & $\begin{array}{l}\text { Os recursos necessários para processar uma classe de } \\
\text { determinado produto são mantidos próximos, ou seja, os } \\
\text { recursos transformados movimentam-se para uma área } \\
\text { específica da operação - a célula - na qual todos os } \\
\text { recursos necessários para a transformação do produto } \\
\text { estão presentes }\end{array}$ & $\begin{array}{l}\text { Lanchonete de supermercado, } \\
\text { shopping de lojas de fábricas, } \\
\text { feiras de exposição }\end{array}$ \\
\hline $\begin{array}{l}\text { Posicional ou } \\
\text { por posição } \\
\text { fixa }\end{array}$ & $\begin{array}{l}\text { O recurso transformado não se move ou tem mobilidade } \\
\text { muito baixa, em outras palavras, o produto fica } \\
\text { estacionário e os recursos de transformação se movem } \\
\text { conforme necessário }\end{array}$ & $\begin{array}{l}\text { Projetos de grandes construções } \\
\text { (estradas, pontes, usinas, etc) e de } \\
\text { produtos com movimentação } \\
\text { extremamente difícil (cirurgia, } \\
\text { trabalhos artes anais, montagem de } \\
\text { equipamento perigoso, etc) }\end{array}$ \\
\hline
\end{tabular}

Fonte: elaborado a partir de [4][8].

Naturalmente, cada um dos tipos de arranjo físico apresenta vantagens e desvantagens. O arranjo físico por produto permite a produção em massa com grande produtividade, carga de máquina e consumo do material constantes ao longo do processo, controle de produtividade facilitado [8], além de alta padronização e baixa quantidade de estoque intermediário [7]. Por outro lado, é necessário um alto investimento em máquinas, trabalho repetitivo dos operadores, baixa flexibilidade e fragilidade a paralisações e gargalos [8].

$\mathrm{O}$ arranjo físico por processo ou funcional possui alta flexibilidade, operações menos repetitivas, alta variedade e menor investimento em instalações [10]. Em contrapartida, apresenta fluxo longo, menor diluição do custo, dificuldade de balanceamento e exige mão de obra qualificada [8].

Por sua vez, o arranjo físico celular tem como vantagens alta flexibilidade e produtividade, menor estoque em processo, menor movimentação, menor tempo de setup e processos e melhor aproveitamento das pessoas [11]. Como desvantagens, estão a especificidade para uma linha de produto e a dificuldade em elaborar o arranjo [8].

Por fim, o arranjo físico posicional alto nível de customização, alta flexibilidade e pouca ou nenhuma movimentação do produto, porém necessita de alta movimentação de pessoal e equipamentos, mão de obra com múltipla especialização e possui baixa padronização e escala, além da dificuldade no planejamento e controle da produção [10].

\section{II.2. LEAN MANUFACTURING: CONCEITOS E FERRAMENTAS}

O lean manufacturing (ou produção enxuta) é composto por uma filosofia (melhoria contínua, eliminação de desperdícios e participação de todos), técnicas de gestão (e.g. mapa do fluxo de valor, gestão visual, design for manufacturing) e de produção (e.g. kanban, smed, TQM, TPM) [4], e deu origem a outras expressões como lean suppliers, lean logistics e lean warehousing [9].

De acordo com [7], o lean é uma forma de abordar, entender e conduzir as atividades manufatureiras. Para [12] o definem como uma filosofia completa que inclui aspectos de administração de materiais, gestão da qualidade, arranjo físico, projeto do produto, organização do trabalho e gestão de recursos humanos. 


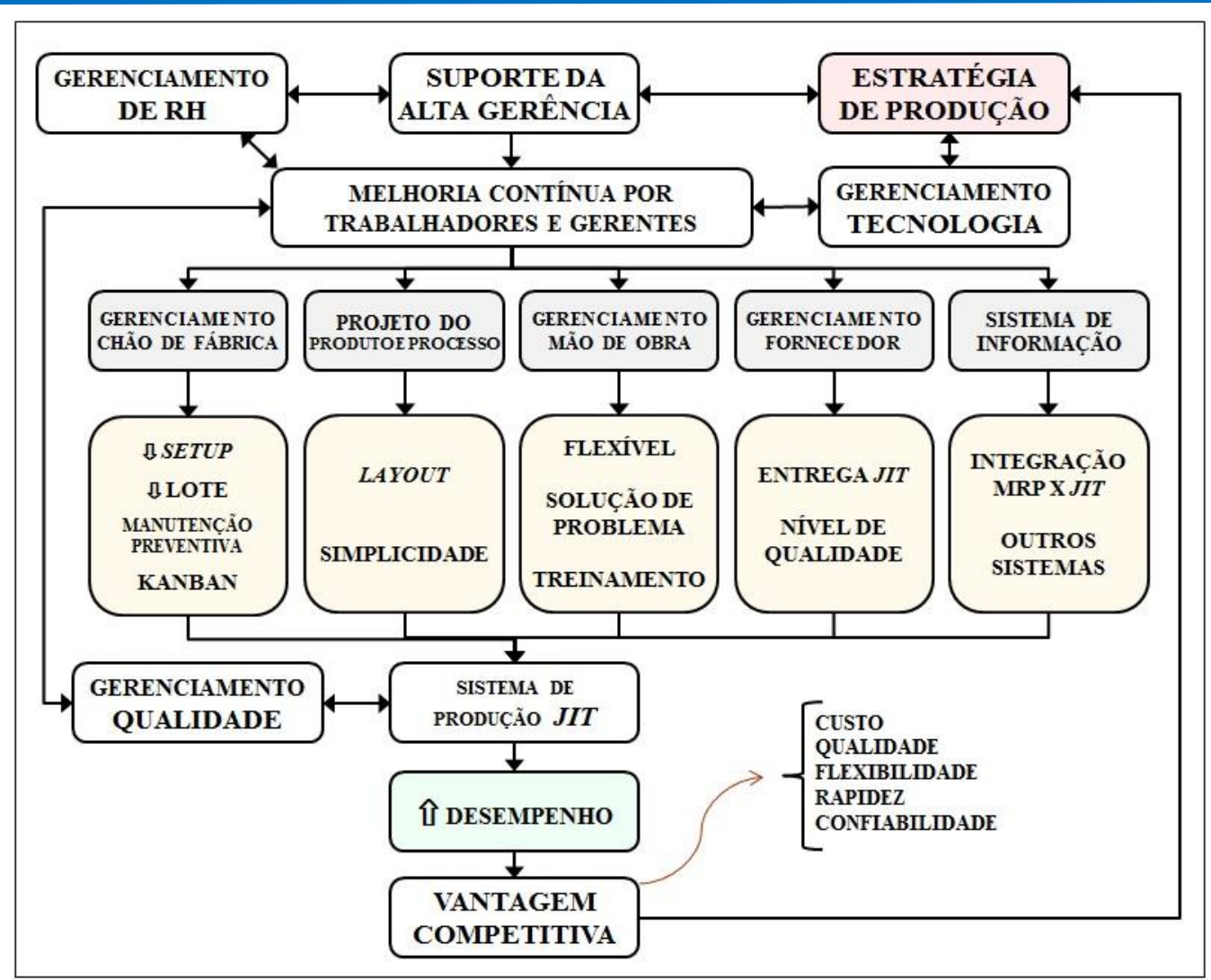

Figura 2: Filosofia e técnicas do lean manufacturing no sistema de produção.

Fonte: elaborado a partir de [12][13].

Com base na figura 2, é possível observar que o lean manufacturing não se resume a aplicação de ferramentas, e sim permeia todo o sistema de produção. Sua filosofia de melhoria contínua reúne desde a alta gerência até os operadores, influenciando o gerenciamento do chão de fábrica, o projeto de produto e processo, o gerenciamento da mão de obra, o gerenciamento do fornecedor e o sistema de informação. Apoiado pela gestão da qualidade, o sistema de produção JIT (Just in Time) proporcionará, então, vantagem competitiva à empresa quanto ao objetivo de desempenho (custo, qualidade, flexibilidade, rapidez e confiabilidade).

Como dito anteriormente, o pensamento enxuto tem como um de seus pilares a eliminação de desperdícios. Nesse sentido, [14] identifica sete tipos de desperdícios da produção: superprodução (produzir mais do que é necessário), espera (tempo de improdutivo de máquinas, mão de obra e de materiais), transporte (a movimentação de materiais dentro da fábrica), processamento (etapas que podem ser eliminadas), estoque (esconde os problemas reais de produção), movimentação (movimentos inadequados dos trabalhadores para realizar suas tarefas e normalmente é provocada por falta de padrão no trabalho) e retrabalho (repetição de uma tarefa, correção de um produto ou nova fabricação para substituição de produto defeituoso).

Outra técnica comumente utilizada em ambientes lean é o $5 \mathrm{~S}$, que representa um conjunto bem simples de regras para reduzir o desperdício [4], as quais estão resumidas no quadro 2:

Quadro 2: O significado dos 5S.

\begin{tabular}{|c|c|}
\hline $\begin{array}{c}\text { Seiri } \\
\text { (utilização) }\end{array}$ & $\begin{array}{l}\text { Eliminar recursos e materiais não utilizados no local de trabalho visando a liberação de } \\
\text { espaço; manter apenas objetos e dados que são necessários diariamente no local de trabalho }\end{array}$ \\
\hline $\begin{array}{c}\text { Seiton } \\
\text { (ordenação) }\end{array}$ & $\begin{array}{l}\text { Esta etapa consiste em dispor os itens de maneira fácil para serem utilizadas, buscando a } \\
\text { rapidez de acesso aos objetos e dados e diminuindo movimentação desnecessária }\end{array}$ \\
\hline $\begin{array}{c}\text { Seiso } \\
\text { (limpeza) }\end{array}$ & $\begin{array}{l}\text { Limpar o local de trabalho e procurar os focos de sujeira com a intenção de eliminá-los ou } \\
\text { reduzi-los ao máximo, resultando em um ambiente que proporciona maior bem estar e, } \\
\text { consequentemente, maior produtividade }\end{array}$ \\
\hline $\begin{array}{l}\text { Seiketsu } \\
\text { (saúde) }\end{array}$ & $\begin{array}{l}\text { Mudança de cultura das pessoas envolvidas, devendo-se manter as condições físicas e } \\
\text { mentais de traalho favoráveis à saúde }\end{array}$ \\
\hline $\begin{array}{c}\text { Shitsuke } \\
\text { (autodisciplina) }\end{array}$ & $\begin{array}{l}\text { Uma vez cumpridas as etapas anteriores, o comprometimento pessoal com o cumprimento } \\
\text { rigoroso dos padrões éticos, morais e técnicos devem ser aperfeiçoados continuamente }\end{array}$ \\
\hline
\end{tabular}

Fonte: elaborado a partir de [15]. 
Por fim, ressaltasse o chamado kanban que, segundo [4], consiste em um método de operacionalizar o sistema de planejamento e controle puxado, ou seja, é utilizado pelo estágio cliente para avisar seu estágio fornecedor que mais material precisa ser enviado. De acordo como mesmo autor, o kanban pode as sumir divers as formas (e.g. cartão, marcadores plásticos, bolas de pinguepongue, marcações no chão) e tipos (e.g. movimentação, produção).

\section{PROCEDIMENTOS METODOLÓGICOS}

O delineamento da pesquisa foi baseado nas etapas apresentadas por [16] para um estudo de caso: formulação do problema, definição da unidade-caso, elaboração do protocolo, coleta e análise dos dados e preparação do relatório.

$\mathrm{O}$ problema investigado neste trabalho se refere à tomada de decisão sobre o layout, ou seja, a alocação de recursos de maneira a otimizar o fluxo de pessoas e de material.

Para tanto, foi selecionada uma empresa produtora de móveis de alumínio, tendo sido seguidas as seguintes etapas: inicialmente, realizou-se um diagnóstico inicial das possibilidades de melhoria a partir do mapeamento do processo e do fluxo do material; aplicação dos conceitos do 5S; determinação de quadrados kanban; análise do layout atual; e, por fim, proposição do novo layout.

A coleta de dados foi realizada por meio de observação direta durante visitas ao chão de fábrica e de entrevistas com o proprietário e operadores. Assim, foram identificadas as oportunidades de melhoria na visita inicial e, a partir disso, foi realizada a análise e o desenvolvimento de uma proposta de uma nova configuração de recursos produtivos. Por fim, realizou-se a elaboração de um relatório, o qual serviu de base para a redação deste artigo.

\section{ESTUDO DE CASO \\ IV.1. DIAGNÓSTICO INICIAL: MAPEAMENTO DO PROCESSO E DO FLUXO DE MATERIAL}

Inicialmente, foram coletados dados como tempo de ciclo, tempo de setup, número de funcionários em cada processo $\mathrm{e}$ quantidade e ordem dos processos da linha de produção.

Em seguida, realizou-se o mapeamento do processo, sendo possível observar oportunidades de implementação de fluxo contínuo.

Quanto ao layout, foi possível notar que organização dos recursos não favorecia a movimentação de materiais e ferramentas, a limpeza do local de trabalho e a padronização do processo.

\section{IV.2. APLICAÇÃO DOS CONCEITOS DO 5S}

Assim, visando a eliminação de desperdícios e a facilitação das etapas posteriores, foram aplicados os conceitos do $5 \mathrm{~S}$ no chão de fábrica da empresa.

O primeiro passo - Seiri (utilização) - foi manter em cada posto de trabalho somente os materiais/ferramentas que fossem realmente úteis.

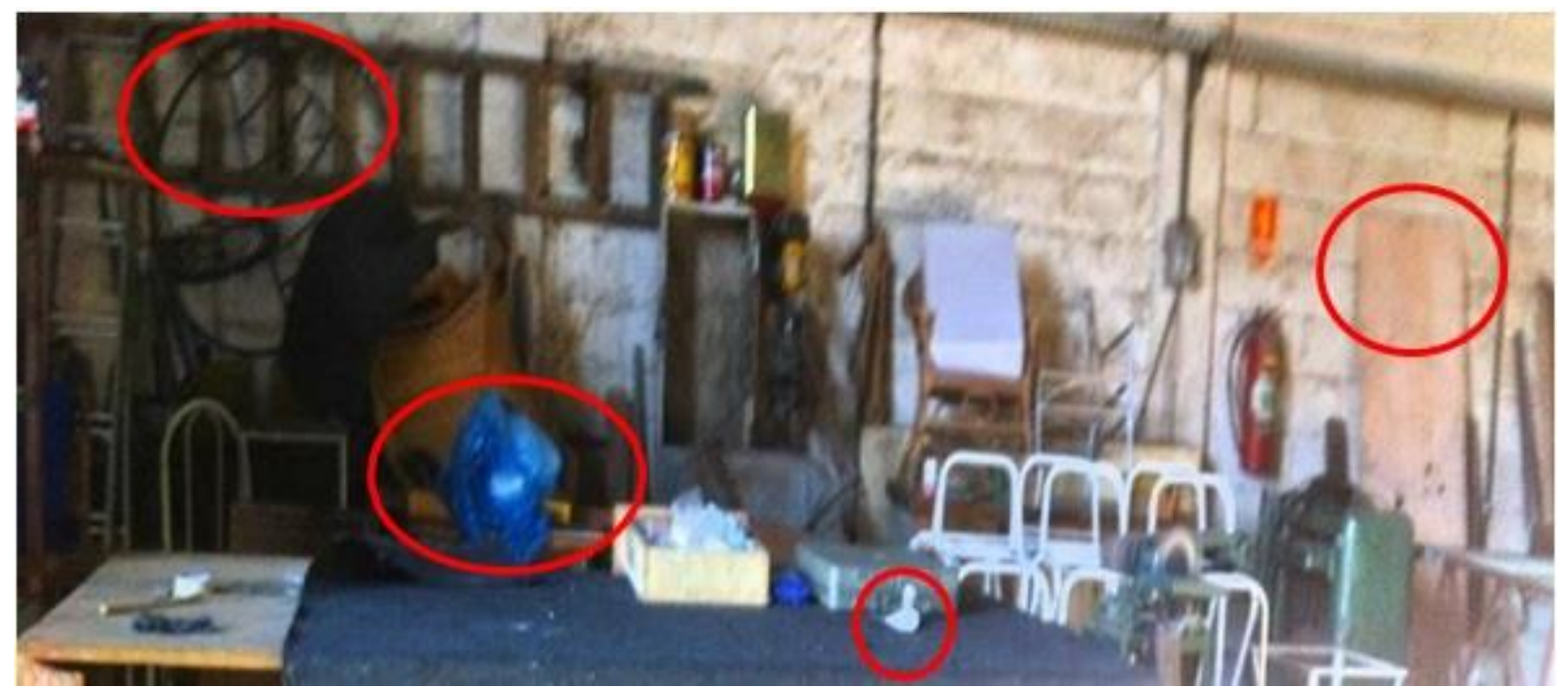

Figura 3: Desperdícios no local de trabalho. Fonte: Autores, (2016).

Como evidenciado na figura 3 , foram eliminados materiais como pedaços de alumínio cortado (sem condição de revenda), sacolas plásticas sem uso, fios metálicos, papeis, entre outros que não agregam valor ao produto.

$\mathrm{Na}$ etapa seguinte - Seiton (organização) - a foi estabelecido foi determinado um local correto para colocar cada ferramenta (que ficavam misturadas) e work in process (explicitado no novo layout por meio de quadrados kanban), eliminando-se desperdícios de tempo e movimento.

A realização do Seiso (limpeza), que teve por objetivo demonstrar condições fora do padrão e potenciais falhas que podem causar problemas no equipamento ou afetar a qualidade, foi possível sugerir melhorias como um quadro de ferramentas, localização correta dos EPI (equipamentos de proteção individual), evitando acidentes e danificação destes materiais. 


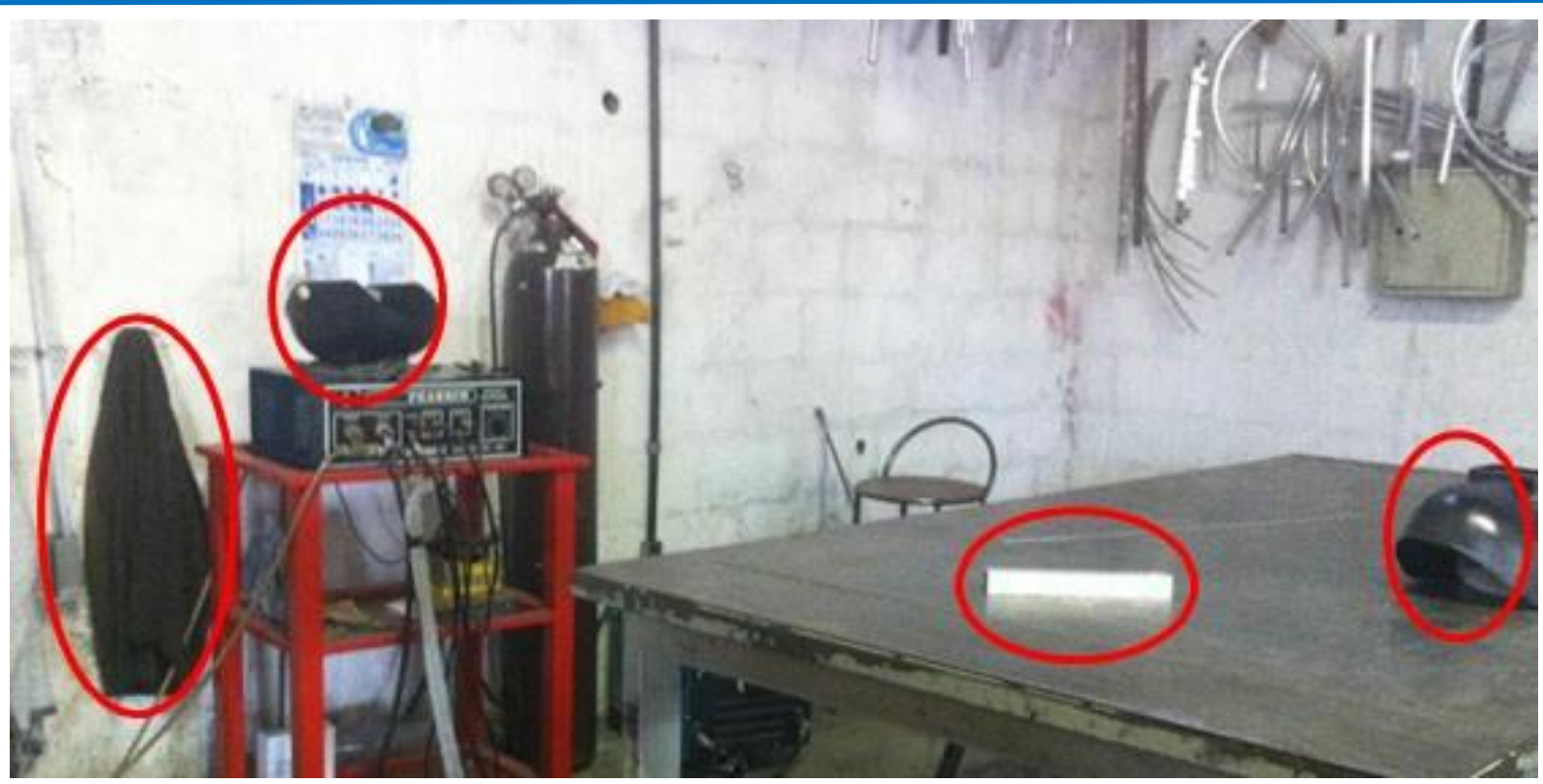

Figura 4: Ferramentas e EPI sem local correto para armazenamento. Fonte: Autores, (2016).

Baseando-se no conceito de Seiketsu (padronização), estabeleceram-se, juntamente com o proprietário e funcionários, normas internar para se monitorare manter as três primeiras etapas, atreladas à última etapa - Shitsuke (disciplina) -, contribuindo para a perpetuação da melhoria continua.

\section{IV.3. DETERMINAÇÃO DE QUADRADOS KANBAN}

Considerando-se a demanda do cliente e que a empresa trabalha em regime de CLT (descontando-se em cada turno um intervalo de 30 minutos), foi possível calcular o takt time da empresa que resultou no valor de 50 minutos/peça.

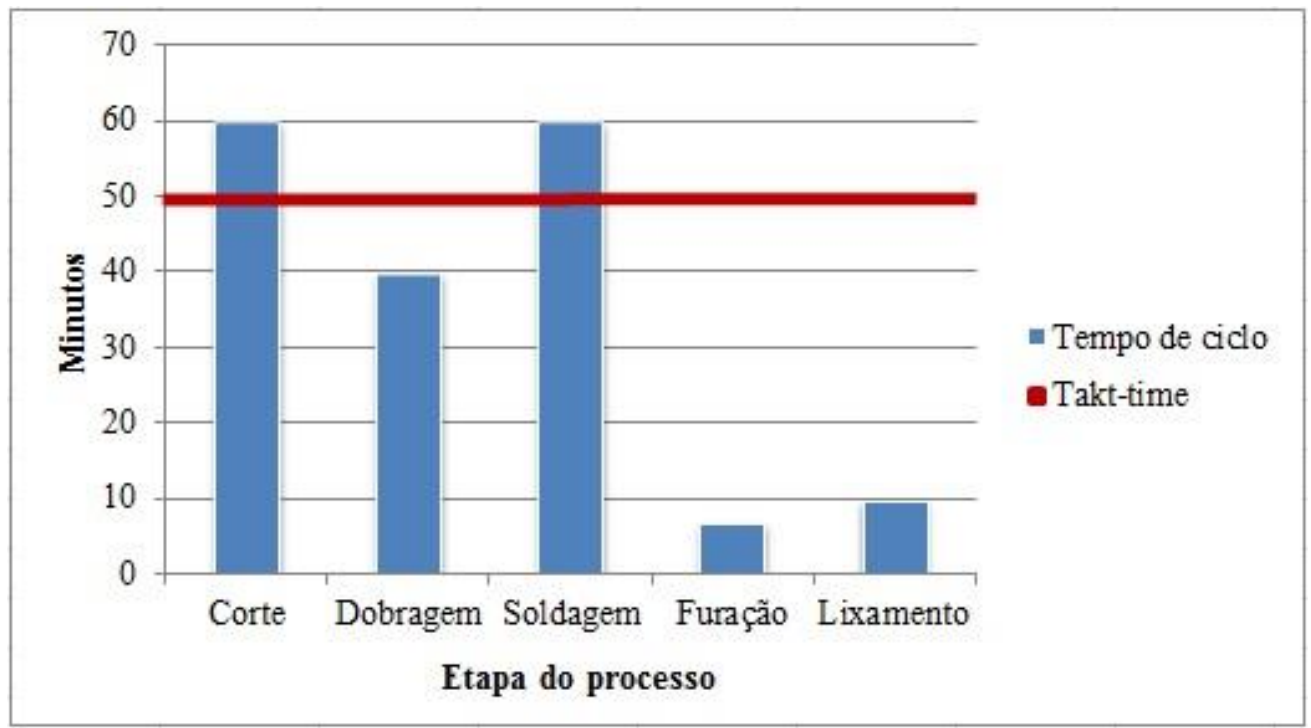

Figura 5: Tempos de ciclo e takt-time. Fonte: Autores, (2016).

Através da análise dos tempos de ciclo de cada etapa do processo (corte, dobragem, soldagem, furação e lixamento) e do takt time, foi identificada a necessidade de implantar três supermercados no chão de fábrica: antes da soldagem, antes da pintura e antes da expedição.

Assim, foi utilizado o sistema kanban, na forma de quadrados kanban, que consistememmarcações no chão de fábrica que indicam locais de armazenamento de uma quantidade predeterminada de material (delimitada pelo espaço da marcação), que ficam à disposição dos clientes internos, isto é, do processo seguinte.

Como mostra a figura 5, onde os processos estão ordenados na ordem de execução, nota-se que o tempo de ciclo da soldagem supera em 20 minutos o anterior imediato (dobragem), sendo possível a implantação de um supermercado para nivelar a produção. O processo de pintura é terceirizado (portanto, não 
consta na figura) e possui lead time muito elevado, levando à necessidade de um segundo supermercado antes do envio da empres a contratada. Por fim, um último espaço de armazenamento foi necessário para os produtos finais.

\section{IV.4. ANÁLISE DO LAYOUT ATUAL E DO FLUXO DE MATERIAIS}

A figura 6 mostra o layout atual da empresa:

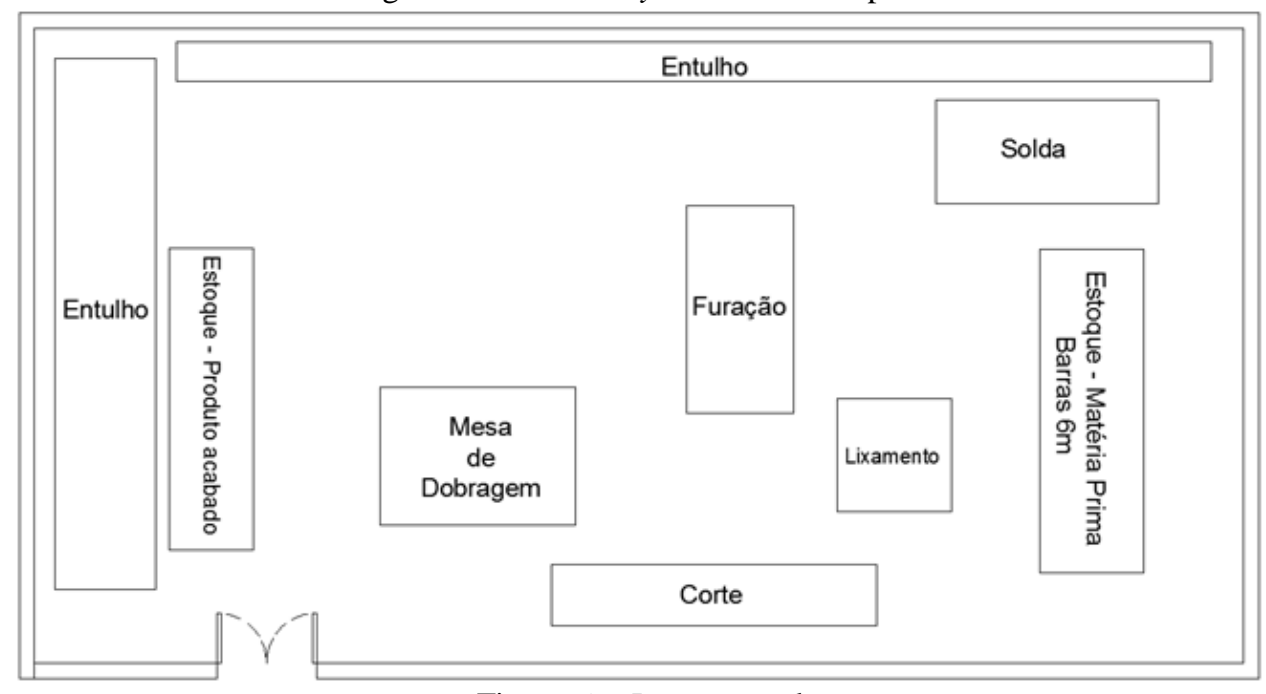

Figura 6 - Layout atual

Fonte: Autores, (2016).

O recebimento da matéria-prima (barras de alumínio) é realizado por um portão localizado à esquerda da planta e, então, é direcionado para o estoque de matéria- prima do outro lado do local.As barras cortadas e logo após direcionadas à mesa de dobragem, onde são utilizados gabaritos para realizar a dobra. $\mathrm{Na}$ etapa seguinte de soldagem, é necessário atravessar os postos de furação e lixamento com todo o material cortado.

As barras soldadas ficam paradas durante 15 minutos para que o material seja resfriado. Após este intervalo, as barras seguem para a furação e, em seguida, passam pelo lixamento para dar acabamento à peça. Assim, a estrutura de alumínio que serve de sustentação para a cadeira segue para o estoque de produtos acabados. Novamente, pode-se observar uma grande distância que deve ser percorrida. Para se entender o fluxo de material na empresa, foi necessário estudar o movimento dos componentes do produto em questão (figura 7):

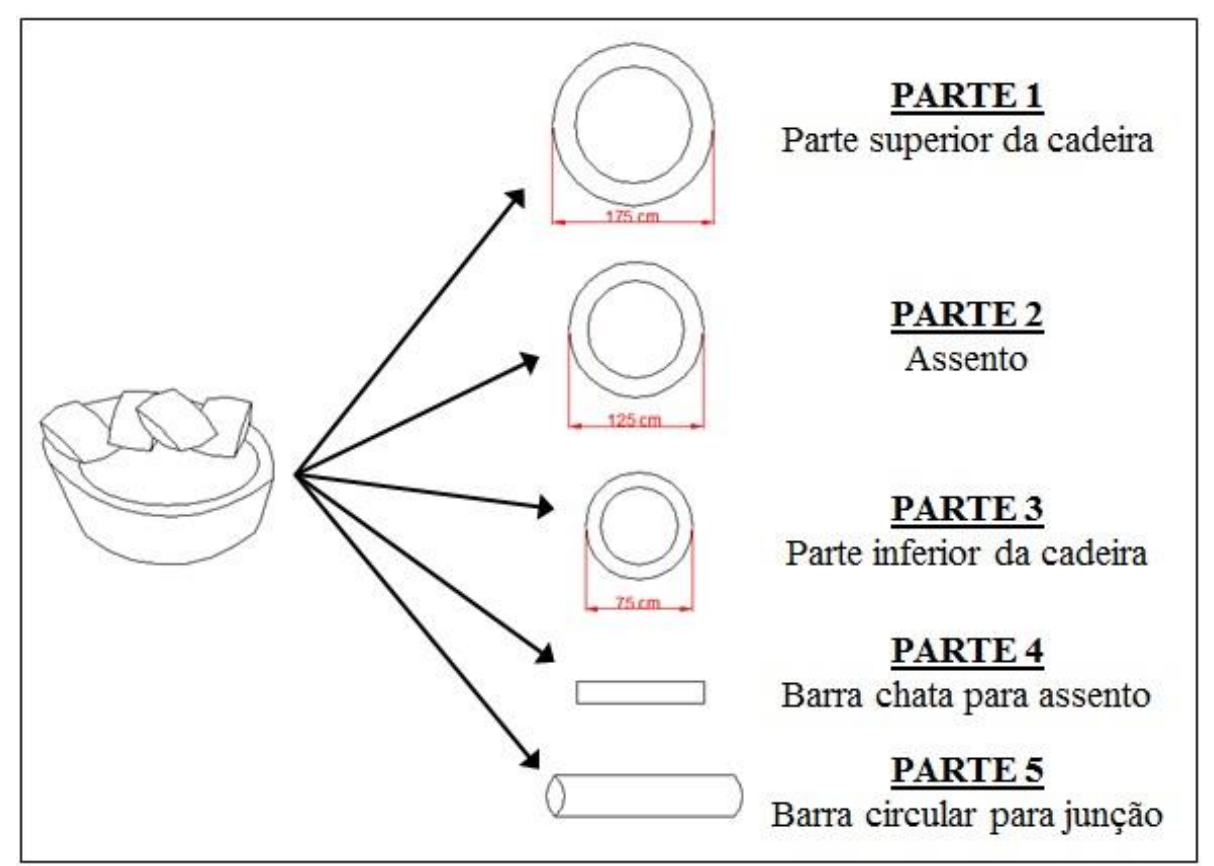

Figura 7: Componentes do produto.

Fonte: Autores, (2016). 
Assim, foram mapeados, para cada componente, os fluxos de movimentação (figura 8), representados da seguinte maneira:

- As setas pretas mostram o fluxo comum a todos os componentes, uma vez que todos chegam como barras de alumínio, são direcionadas ao estoque e em seguida ao corte;

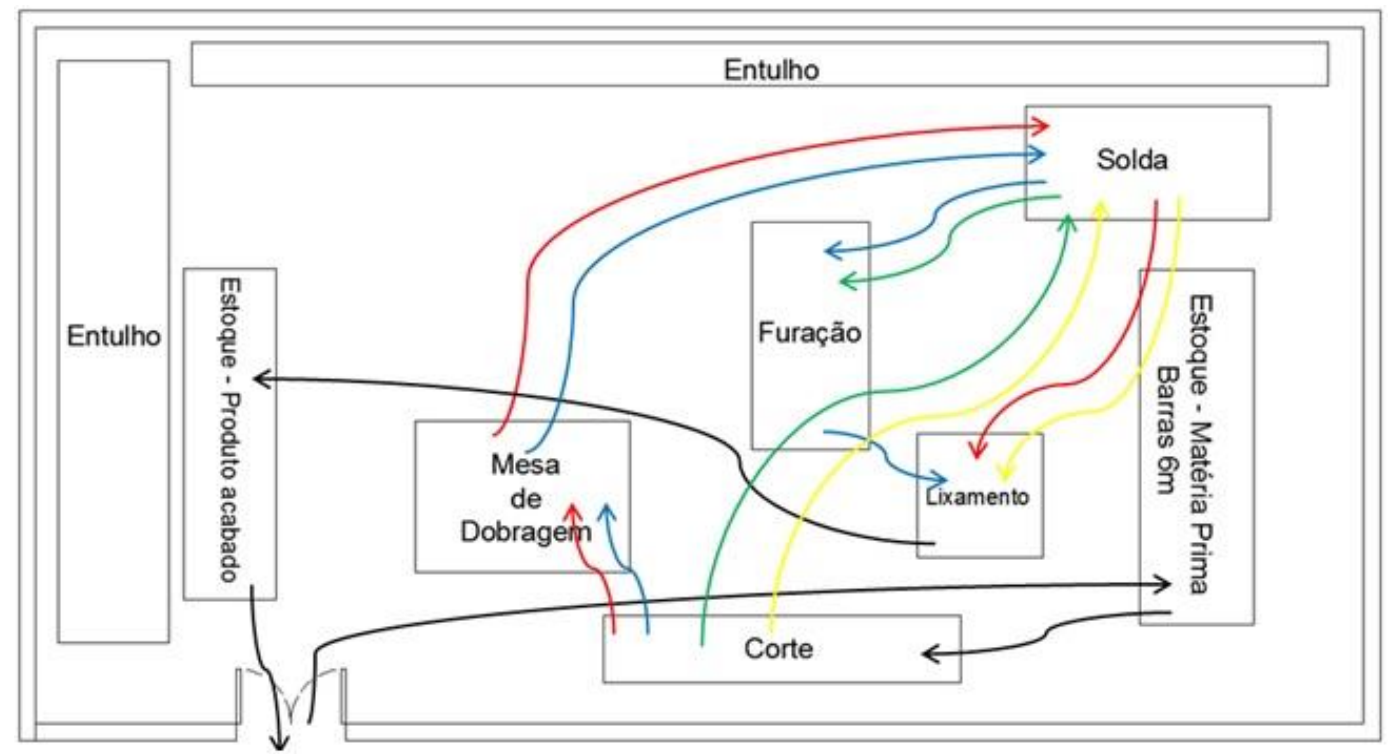

Figura 8 - Fluxo de material no layout atual.

Fonte: Autores, (2016).

Pode-se perceber que o fluxo de material é bastante confuso e as movimentações tem que ser realizadas, muitas vezes, entre os espaços onde se localizam as mesas utilizadas para a realização do processo. Outro fator a ser considerado são os estoques em processo, os quais ficam localizados nos corredores utilizados para a movimentação. Além disso, notam-se distâncias longas entre processos sucessores imediatos.

\section{IV.5. PROPOSIÇÃO DE UM NOVO LAYOUT}

Conhecendo-se os componentes, bem como os processos a que cada um é submetido, foi elaborada a matriz peça-máquina, atribuindo-se o valor 1 quando a peça passa pelo processo e zero, caso contrário.

Tabela 1: Matriz peça-máquina.

\begin{tabular}{|c|c|c|c|c|c|c|}
\hline & \multicolumn{5}{|c|}{$\overline{\text { Peça }}$} \\
\hline & & 1 & 2 & 3 & 4 & 5 \\
\hline \multirow{5}{*}{ 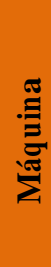 } & Corte & 1 & 1 & 1 & 1 & 1 \\
\hline & Dobramento & 1 & 1 & 1 & 0 & 0 \\
\hline & Soldagem & 1 & 1 & 1 & 1 & 1 \\
\hline & Furação & 0 & 1 & 0 & 1 & 0 \\
\hline & Lixamento & 1 & 1 & 1 & 0 & 1 \\
\hline
\end{tabular}

Fonte: Autores, (2016).

Para definição da melhor forma de organização das máquinas, foi utilizado o algoritmo Close Neighbour Algorithm (CNA), proposto por [17]. De acordo com os autores, é necessário a construção da matriz máquina-máquina (ou matriz B), atribuindose o número de componentes comuns a cada par de máquinas:
- As setas vermelhas repres entam os componentes 1 e 3;

- As setas verdes e azuis representam, respectivamente, os componentes 4 e 5 . 
A figura 9 mostra o novo layout proposto, assim como os novos fluxos de material:

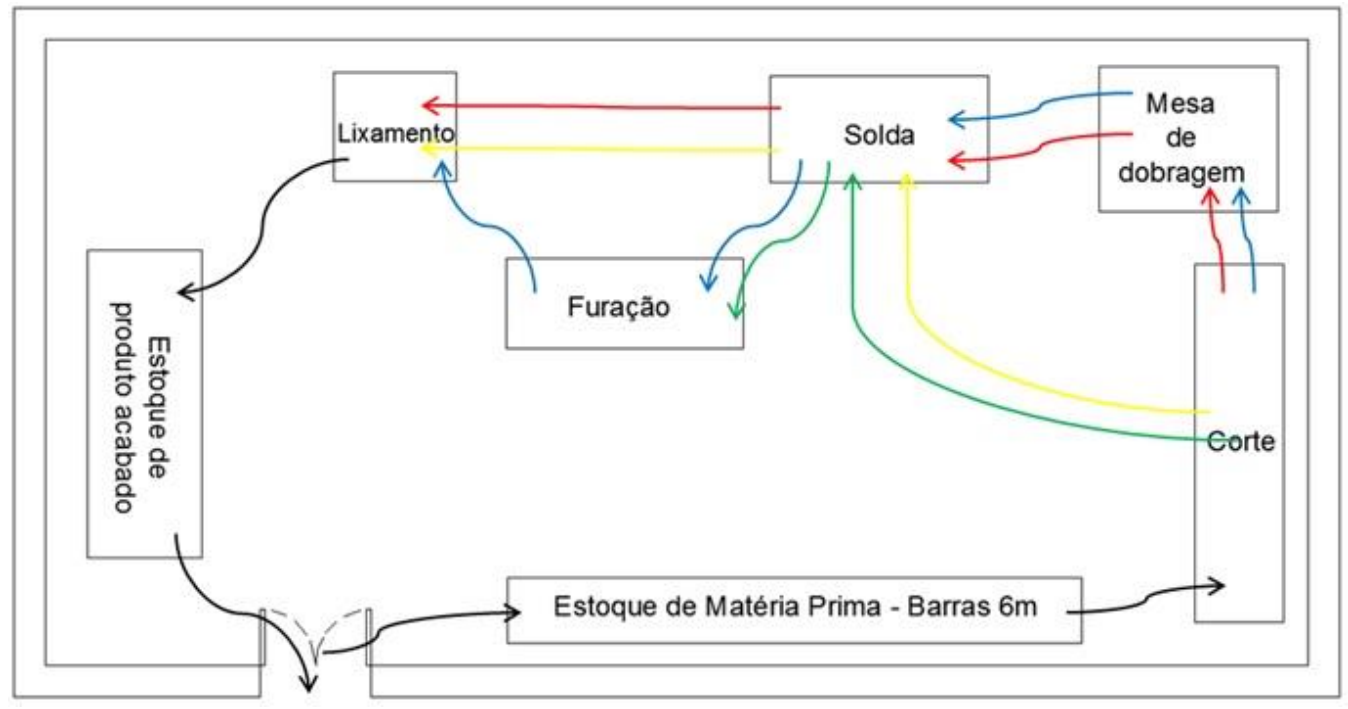

Figura 9:Layout proposto e novos fluxos de material.

Fonte: Autores, (2016).

Observa-se que com a nova configuração do layout a quantidade de setas diminuiu, ou seja, a quantidade de movimentações necessárias foi reduzida. Além disso, nota-se que o tamanho das setas também diminuiu, o que representa uma diminuição das distâncias a serem percorridas. Outro importante fator é que não há mais cruzamento entre setas, além de não ser mais necessário atravessar corredores entre as máquinas, o que representa uma simplificação do trajeto, contribuindo, assim, para um melhor fluxo do material na fábrica, além de proporcionar um ambiente mais limpo, seguro e organizado.

\section{CONSIDERAÇÕES FINAIS}

Este estudo teve como objetivo apresentar a análise e a proposição de um novo layout sob a ótica do lean manufacturing a partir do caso de uma empresa do ramo de produção de móveis de alumínio. Por meio de visitas à empresa, observação direta do chão de fábrica e entrevistas com funcionários e proprietário, foi possível coletar dados suficientes para a proposição de diversas melhorias. Fundamentadas nos conceitos do 5S [14], melhorias foram propostas quanto à utilização ou Seiri (eliminação de que não eram úteis aos postos de trabalho), organização ou Seiton (estabelecimento de local correto para armazenar ferramentas e estoques em processo), limpeza ou Seiso (identificação de potenciais falhas relacionadas à qualidade e segurança), padronização ou Seiketsu (estabelecimento de normas internas para manter o 5S) e disciplina ou Shitsuke (perpetuação da melhoria contínua).

Contribuiu-se também através da análise dos tempos de ciclo de cada etapa do processo (corte, dobragem, soldagem, furação e lixamento) e do takt time, tendo sido possível a identificação da necessidade de três supermercados, utilizando-se o conceito de quadrado kanban. Por fim, apoiando-se nas etapas anteriores, a principal contribuição do estudo foi a proposição de um novo layout para a empresa. Como auxílio do algoritmo Close Neighbour Algorithm [17], foram determinadas duas células de produção (uma célula com as máquinas de corte, dobramento, soldagem e lixamento e outra apenas com a furação), resultando em benefícios como redução de distâncias, redução de movimentações desnecessárias, maior simplificação do trabalho dos operadores, ambiente mais limpo, seguro e organizado. Assim, este estudo atingiu o seu objetivo na medida em que apresentou um caso de proposição de um novo layout que atende de diversas maneiras aos princípios do lean manufacturing, ou seja, da melhoria contínua, eliminação de desperdício e participação de todos.

\section{REFERÊNCIAS}

[1] Zhenyuan, Jia, Xiaohong, Lu, Wei, Wang, Defeng, Jia e Lijun, Wang.. Design and implementation of lean facility layout system of a production line. International Journal of Industrial Engineering, v. 18, is sue 5, p. 260-269, 2011.

[2] Shahin, Arash e Poormostafa, Mehdi. Facility layout simulation and optimization: an integration of advanced quality and decision making tools and techniques. Modern Applied Science, v.5, $\mathrm{n}^{\circ} 4$, p. 95-111, 2011.

[3] Shewale, Pramod, Shete, Manmath e Sane, S. Improvement in plant layout using systematic layout planning (SLP) for increased productivity. International Journal of Advanced Engineering Research and Studies.v.1, n.3, 2012.

[4] Slack, Nigel, Chambers, Stuart e Johnston, Robert. Administração da produção. ( $2^{\mathrm{a}}$ ed.). São Paulo: Atlas, 2002.

[5] MDIC. Ministério do Desenvolvimento, Indústria e Comércio Exterior. Cadeia Produtiva de Madeira e Móveis. Legislação Móveis. Disponível em: http://www.mdic.gov.br/legislacao/9as suntos/categ-comercio-exterior/476-regime-de-autopecas-naoproduzidas-ex-tarifarios-de-autopecas-12. Acesso em dez. 2016.

[6] GAITHER, Norman e FRAZIER, Greg. Administração da Produção e Operações ( $8^{\text {a }}$ ed.). São Paulo: Thomsom Learning, 2002. 
[7] MOREIRA, Daniel Augusto. Administração da Produção Operações. ( $2^{\mathrm{a}}$ ed.). São Paulo: Cengage Learning, 2011.

[8] Peinado, Jurandir e Graeml, Alexandre. Administração da Produção: Operações Industriais e de Serviços. Curitiba: UnicenP, 2004.

[9] Jacobs, Robert e Chase, Richard. Operations and Supply Chain Management (13 ${ }^{\mathrm{a}}$ ed.). New York: McGra-Hill, 2011.

[10] CORRÊA, Henrique e CORRÊA, Carlos. Administração da Produção e Operações ( $3^{\mathrm{a}}$ ed.). São Paulo: Atlas, 2012.

[11] Liker, jeffrey. O modelo Toyota: 14 princípios de gestão do maior fabricante do mundo. Porto Alegre: Bookman, 2004.

[12] Corrêa, Henrique e Gianesi, Irineu. Just in time, MRP II e OPT: um enfoque estratégico ( $2^{\mathrm{a}}$ ed.). São Paulo: Atlas, 2014.

[13] Vollmann, Thomas, Berry, William, Whybark, David e Jacobs, Robert. Sistemas de Planejamento e Controle da Produção para Gerenciamento da Cadeia de Suprimentos ( $5^{\text {a }}$ ed.). São Paulo: Bookman, 2006.

[14] Shingo, Shigeo. Sistema Toyota de Produção: Do Ponto de Vista de Engenharia de Produção. Porto Alegre: Bookmann, 1996.

[15] KNOREK, Reinaldo, e Olvieira, Jean. Gestão do agronegócio: implantação do sistema de qualidade total utilizando o programa $5 \mathrm{~S}$ na indústria ervateira. Revista de Administração Geral, v. 1, nº 1, p. 89-109, 2015.

[16] Gil Antônio Carlos. Como elaborar projetos de pesquisa ( $5^{\text {a }}$ ed.). São Paulo: Atlas, 2016, 184 p.

[17] Boe, Warren e Cheng, Chun. A close neighbour algorithm for designing cellular manufacturing systems. International Journal of Production Research, v. 29, issue 10, p. 2097-2116, 1991. 